\section{CESSATION OF TACHYCARDIA ON THE OUTBREAK OF SPONTANEOUS PERSPIRATION.}

BY SIR THOMAS OLIVER, M.D. GLASG., F.R.C.P. LOND. PROFESSOR OF THE PRINCIPLES AND PRACTICE OF MEDICINE, UNIVERSITY OF DURHAM COLLEGE OF MEDICINE, NEWCASTLE-UPON-TYNE.

RECENTLY I saw in consultation with Dr. S. D. Metcalfe, of Benwell, Newcastle-upon-Tyne, a man of sedentary employment, aged 28 years, the subject of tachycardia, who had rapidily become cyanosed and who was dangerously ill. The patient, a well-built man and married, had three days previously, when at work, been seized unexpectedly with vomiting, and immediately afterwards tachycardia developed. The vomiting kept recurring, and was rather a distressing symptom. This was not the first oecasion on which the patient had suffered from such a seizure. Fight years ago, just before his marriage, he had an attack; three years ago he was similarly held, and since then he has had minor seizures, but with the exception of the original attack, to be subsequently mentioned, in none of them had he been so severely held as in this last. Until his recovery from this last attack no explanation of the seizures was forthcoming. It now appears that at the age of 15 after running a few miles, during which he stumbled twice from exhaustion, his heart began to beat violently and the beats were quickened. For two days after running he lay in bed unconscious. The patient is extremely abstemious and is only a light smoker. There is no rheumatic history, nor is there any abnormal physical condition of the body ascertainable through which the attack could be regarded as having developed reflexly.

When I saw patient he was lping in bed, calm and composed. There was no indication of nervous excitement, and, considering the rate at which the heart was beating, there was an absence of respiratory distress. The face was pale, and although the lips were cyanosed the blueness was less than it had been two to three hours previously. The pulse was extremely rapid, about 200 per minute; not all the pulsations reached the wrist. On examining the heart the apex beat was felt fully one inch external to the nipple line and slightly higher up than usual. At and internal to the apex beat a loud, blowing, systolic murmur could be heard, but no second sound, while external to the nipple line, in addition to the systolic murmur, a faint but normal second sound could be heard. The systolic murmur was audible over the lower part of the sternum, also over the base of the heart, where it was followed by a feeble second sound. Over the præcordium generally all that could be heard was an almost constant blowing, systolic murmur. The area of cardiac dullness was increased transversely. The lungs were normal. There were marked epigastric pulsation and an enlarged liver. 'The urine was normal. There was neither adema nor rise of temperature. A moderate amount of sleep and physical quietude had been secured by the hypodermic administration of morphia, strychnine, and digitalin. As vomiting still continued an effervescing soda, bismuth, bromide, and belladonna mixture was ordered, and this gave relief.

Dr. Metcalfe, who had examined the patient shortly before the attack, was able to assure me that the heart was at that time normal and that the apex beat was then inside the nipple line. Within three days, therefore, this man's heart had rapidly dilated; the left ventricle had expanded as shown by the situation of the apex beat, and the right had dilated as indicated by the epigastric pulsation, while the widely distributed systolic murmur was additional evidence of an increasing enfeeblement of the myocardium generally.

The patient's condition was sufficient to cause anxiety on account of the recurrent vomiting and the supervention of cyanosis upon pallor. Later on, during the evening of my visit, perspiration broke forth. Shortly after this the patient sat up in bed, and said now that he had begun to sweat he knew from past experience he would soon be better. His expectations were confirmed, but not until another experience of previous attacks had become realised in the advent of pain located over the manubrium sterni and base of the heart, attended by a sense of great difficulty of breathing as the beat of the heart slackened and the pulse-rate fell.
Having this presage of recovery the patient had on the whrle a comfortable night.

Next morning the pulse had fallen to 74 , epigastric pulsation had disappeared, the systolic murmur was inaudible, and the apex beat had slightly receded. The rapid decline of the tachycardia and disappearance of the physical signs of cardiac dilatation upon the outbreak of spontaneous perspiration are the main features in the case. It is not unusual for tachycardia to suddenly cease. This has been known to occur, for example, after the emission of a large quantity of urine.

We searched for an exciting cause of the attack of tachycardia in our patient, but without success. The illness came with a vomiting, and it disappeared with a perspiration ; for two days the perspiration continued. The thyroid gland was normal, so that the influence of an internal secretion from this gland can be ignored. The view we took at the time was that the attack was one of central origin and due either to loss of vagal control or to increased discharge from the accelerator nerve centres. There was nothing to indicate that the attack was consequent upon any primary derangement of cardiac ganglia, for although several of the pulse beats failed to reach the wrist this circumstance did not seem to point to extra-auricular systoles so much as to failure of the driving power of the left ventricle. The bundle of His when it has undergone fibrosis is said to cause tachycardia; so, too, does arterio-sclerosis of the cardiac coronary arteries, but the rapidity with which the symptoms and physical signs disappeared, also the outbreak of spontaneous perspiration, point to functional derangement of the central nervous system. I have seen tachycardia cause death through myocardial and general exhaustion. In our patient there was never any of the sense of dread or distress which are sometimes observed in angina pectoris.

Newcastle-upon-Tyne.

\section{attedical Socteties.}

\section{ROYAL SOCIETY OF MEDICINE.}

\author{
SECTION OF SURGERY.
}

Treatment of Convalescent Soldiers by Physioal Means.

A MEETING of this section was held on July 21st, Sir RICKMAN GODLEE, K.C.V.O., being in the chair.

Sir RICKMAN GODLEe announced that Sir Alfred Keogh, Director-General, had written expressing his regret that he could not be present, as he had hoped, and stating that General M. W. Russeil was representing him at the meeting. Sir Rickman Godlee extended the welcome of the society to the staffs of the medical services of the four colonial contingents, and invited them and any other visitors to take part in the discussion should they so desire.

Major TAIT MCKENzIE, R.A.M.C., read a paper on the Treatment of Convalescent Soldiers by Physical Means. $\mathrm{He}$ said the military general hospital was very much like a general post-office in one respect, for in the latter the material was sorted out into first-class, second-class, and third-class matter. The first-class matter in these hospitals was distributed to various hospitals for operation or other treatment, and usually found its way back into the firing line within a month or so of the commencement of the disability. It was usual for the second-class matter to stay a little longer in a convalescent hospital, but most of these patients were back at the front in the course of six or eight weeks. But there remained the third-class matter, which was not brought back by these two processes. At the beginning of the war this material accumulated in various depôts and became an increasing encumbrance to the military authorities. It was to provide for this class of case, which could not be brought back in a few days or weeks or within six months, that the "Command Depôt" was established. His own experience was obtained at the Heaton Park Depôt. In the first year of the war so many urgent matters required attention that the Director-General was unable to provide for the situa. tion until the Command Depôt was established for the reception of the more prolonged cases. This convalescent hospital was under the Royal Army Medical Corps, and a limit of six months was placed on the time necessary to treat the 